\title{
Quasi-realism and normative certitude
}

\author{
Stina Björkholm ${ }^{1}\left({ }^{1} \cdot\right.$ Krister Bykvist $^{1} \cdot$ Jonas Olson $^{1}$ (I)
}

Received: 25 June 2019 / Accepted: 23 January 2020 / Published online: 1 February 2020

(c) The Author(s) 2020

\begin{abstract}
Just as we can be more or less certain that there is extraterrestrial life or that Goldbach's conjecture is correct, we can be more or less certain about normative matters, such as whether euthanasia is permissible or whether utilitarianism is true. However, accommodating the phenomenon of degrees of normative certitude is a difficult challenge for non-cognitivist and expressivist views, according to which normative judgements are desire-like attitudes rather than beliefs (Smith, in: Evaluation, Uncertainty, and Motivation. Ethical Theory and Moral Practice 5: 305-320, 2002). Several attempts have been made on behalf of non-cognitivism and expressivism to meet the challenge (Lenman in: Non-cognitivism and the dimensions of evaluative judgment, Brown Electronic Article Review Service, 2003; Ridge in Synthese 2003. https://doi.org/10. 1007/s11229-018-1884-7; Ridge in: Shafer-Landau (ed) Studies in metaethics, Oxford University Press, Oxford, 2007; Sepielli in Philos Stud 160: 191-207, 2012; Eriksson and Francén Olinder in Aust J Philos 94: 719-735, 2016). These attempts have all been found wanting (Bykvist and Olson in Philos Q 59:202-215, 2009, Aust J Philos 95:794-799, 2017; Bykvist and Olson 2012). Michael Ridge has recently offered a quasi-realist solution, according to which expressivists can say exactly what cognitivists say about certitude, including normative certitude. In this paper, we explain the basic problem and Ridge's quasi-realist solution. We then argue that the quasi-realist account of normative certitude faces severe difficulties that do not arise for cognitivist accounts, according to which normative judgements are beliefs.
\end{abstract}

Keywords Normative certitude · Credences · Quasi-realism · Expressivism · Non-cognitivism

\footnotetext{
Stina Björkholm

stina.bjorkholm@philosophy.su.se

Krister Bykvist

krister.bykvist@philosophy.su.se

Jonas Olson

jonas.olson@philosophy.su.se

1 Department of Philosophy, Stockholm University, Stockholm, Sweden
} 


\section{Introduction: non-cognitivism, normative certitude, importance, and quasi-realism}

An undisputable feature of normative judgments is that they vary in degrees of certitude, just like non-normative judgments do. Just as one can be more or less certain that there is extraterrestrial life or that Goldbach's conjecture is correct, one can be more or less certain that euthanasia is permissible or that utilitarianism is true. Recent debate has revealed that this observation is very difficult to accommodate for non-cognitivist theories of normative judgement. ${ }^{1}$

If normative judgments are beliefs, it is no more problematic to account for degrees of normative certitude than to account for degrees of non-normative certitude. But if normative judgments are non-cognitive, desire-like, states, how are we to make sense of degrees of normative certitude? For example, what is it to be certain that female circumcision is morally wrong and less than certain that male circumcision is wrong?

There is also another dimension of normative judgment, which is often called importance. For example, it is a common thought that it is more important to save lives than to keep promises. This feature is not difficult for cognitivism to accommodate; to judge that saving lives is more important than to keep promises is simply to believe that saving lives is more important than keeping promises. According to traditional versions of non-cognitivism, however, non-cognitive, or desire-like, attitudes have no normative content. It is therefore unclear whether traditional versions of noncognitivism can accommodate normative importance.

Note that certitude and importance are two separate dimensions of normative judgment that can vary independently. ${ }^{2}$ For example, one can be highly certain that keeping promises is not of great importance (that breaking promises is a minor wrong) and one can be moderately certain that euthanasia is of great importance (e.g. that it is seriously wrong). This means that certitude and importance cannot both be accommodated in terms of strength or intensity of non-cognitive, or desire-like, attitude. It appears, then, that desire-like attitudes do not have enough structure to accommodate both certitude and importance in the right way.

We said initially that it is an undisputable feature of normative judgements that they vary in certitude. But perhaps an unflinching defender of non-cognitivism could argue that the view that normative judgements vary in certitude in the first place stems from a misconception. Whatever the prospects of such an endeavour, it is not an option for quasi-realists, who are the contemporary heirs of traditional non-cognitivism. Quasirealists aspire to accommodate apparent realist- and cognitivist-seeming features of normative judgement, without committing to a realist ontology and without abandoning the idea that normative judgements express non-cognitive attitudes. Normative

\footnotetext{
1 The problem was stated in Smith (2002), and further developed in Bykvist and Olson (2009). Several attempts have been made on behalf of non-cognitivism and expressivism to solve the problem (Lenman 2003; Ridge 2003, 2007; Sepielli 2012; Eriksson and Francén Olinder 2016). These attempts have all been found wanting (Bykvist and Olson 2009, 2012, 2017).

${ }^{2}$ It is worth mentioning that there is a third feature, namely that moral judgments can be more or less robust in the sense that they are more or less stable under the impact of new information and further reflection. It is possible to hold a very robust belief with low certitude and vice versa, so these features must also be allowed to vary independently. See Bykvist and Olson (2009).
} 
judgements' varying degrees of certitude is clearly among the realist- and cognitivistseeming fetures that a successful quasi-realist theory must accommodate.

In previous work, two of us have argued that extant non-cognitivist accounts of normative certitude, including ecumenical expressivist accounts, fail (Bykvist and Olson 2009, 2012, 2017). Michael Ridge has recently argued that quasi-realists can do better (Ridge 2018). In Sect. 2, we consider Ridge's refined version of the view that degrees of certitude reduce to betting dispositions. As Ridge is aware, this kind of approach faces many general problems that strike equally against its cognitivist and non-cognitivist versions. Section 3 considers and rejects Ridge's claim that quasi-realists can simply mimic whichever account of certitude cognitivists take to be most plausible. We conclude that quasi-realism fails to provide a non-cognitivist or expressivist account of normative certitude.

\section{Betting accounts of certitude and Ridge's refinements}

Well in line with the quasi-realist spirit, Ridge starts by looking at what realists say, or should say, about certitude, and then argues that quasi-realists can say exactly the same thing. As he notes, however, there is no perfect consensus about what credences are. Pending an account of what credences are, there is no way of knowing whether such an account is available to the quasi-realist (Ridge 2018, p. 6). We shall argue, however, that regardless of which theory of degrees of certitude is in the end most plausible, the onus is on quasi-realists to demonstrate that normative certitude is no more problematic than non-normative certitude. And here they face severe trouble.

So, what is it that cognitivists say, or should say, about certitude, according to Ridge $?^{3}$ His answer is that a 'relatively orthodox conception understands certitude very roughly in terms of counterfactual betting behavior.' (2018, p. 2, emphasis added). A little less roughly, there are the following three main possibilities: (i) an agent's betting dispositions are indicative of her certitude; (ii) an agent's certitude supervenes on her betting dispostions; (iii) an agent's certitude reduces to her betting dispositions.

Ridge argues initially that quasi-realism is compatible with a variety of more precise ways of understanding certitude in terms of betting dispositions, but in the course of discussion, he ends up endorsing (iii). ${ }^{4}$ Ridge thus accepts the betting interpretation not merely as an epistemic view, according to which an agent's betting dispositions are evidence of her certitude - a view that is widely held at least for certain kinds of credences - but also as a metaphysical view that reduces credences to counterfactual

\footnotetext{
3 In the remainder of this paper, we take cognitivism to be the view that normative and non-normative judgements are both representational states-commonly known as beliefs - that differ only in kinds of content. We bear in mind that quasi-realists sometimes claim to be cognitivists. For example, as we shall see below (Sect. 3), Ridge claims to accommodate normative beliefs, but he holds that normative beliefs are non-representational states. (In his paper, Ridge takes his opponents to be realists. Clearly, however, one need not be a realist in order to be a cognitivist. Error theorists, for example, are cognitivists but not realists.).

4 Ridge says that 'the view on offer should be that to assign a credence of .5 to a proposition p just is to be disposed to engage in such-and-such betting behavior' and that 'states of mind are, in effect, reduced to sets of dispositions' (Ridge 2018: p. 15 emphases preserved; 16, emphasis added).
} 
betting behaviour-a view that has very few adherents in these post-operationalist times. 5

The attempt to understand certitude in terms of betting dispositions traditionally involves monetary bets, since money is a unit that is available, quantifiable, easily dividable and desired by (almost) everyone (Eriksson and Hájek 2007, p. 186). Depending on whether one accepts (ii) or (iii) or merely (i) above, the basic thought is that an agent is more confident that $p$ than that not- $p$ if she is disposed to take the bet (€10 if $p$ is true, $€ 0$ if not- $p$ is true) over the bet (€0 if $p$ is true, $€ 10$ if not- $p$ is true), or merely that her disposition to take the former bet over the latter is evidence that she is more confident that $p$ than that not- $p$.

Each extant version of (i), (ii) and (iii) faces a number of well-known problems, helpfully explaned in Eriksson and Hájek (2007). Here we mention only a few of them, focusing on their ramifications for Ridge's views about normative certitude.

First, the narrow focus on monetary bets is problematic since some people care very little or not at all about money, and since money has diminishing marginal utility for most people. Clearly, such variations in attitudes to money should not affect degrees of certitude, no matter whether we are talking about descriptive or normative certitude.

Ridge is aware of this problem. In response to it, he proposes a broader account of betting, 'understood roughly in terms of what payoffs would induce the agent to risk a given cost on the truth of the proposition, where 'cost' and 'payoff' are understood in terms of things the agent cares about' (Ridge 2018, p. 6).

To see what Ridge's account amounts to when it is applied to normative certitude, let us follow him in considering the proposition that lying is wrong. How confident are you that this proposition is true? According to Ridge:

[t]his will be fixed by how much of what [you] care about [you are] disposed to risk on the truth of that proposition. We determine this by going to the nearest possible worlds in which [you] believe that the truth of the proposition determines how much utility [you] will derive from acting in one way rather than another and then 'see what [you] choose' in that world [sic]. (2018, p. 10)

What you care about, and what determines how confident you are that lying is wrong, might be to act rightly:

A simplistic approach would be to assume that in the nearest possible world the agent cares about doing the right thing, say, and believes that the truth of the proposition in question bears on whether, in performing a given action he would thereby satisfy his preference to behave rightly. (2018, p. 10)

As Ridge points out, the preference or desire in question must be a desire de dicto to do the right thing. ${ }^{6}$ While Ridge seems initially to propose this view only for

\footnotetext{
5 Not even Ramsey, who many see as one of the forefathers of the reductive view, accepts such a reduction. What he says is much more qualified. Talking about his theory of credence, he says 'I only claim for what follows approximate truth, or truth in relation to this artificial system of psychology, which like Newtonian mechanics can, I think, still be profitably used even though it is known to be false.' Ramsey (1926), p. 175.

6 If it were a desire de re to do the right thing, 'we would be testing the agent's credence in the truth of the descriptive content they take to be right-making/constituting rather than their credence in the normative content itself' (2018, p. 10).
} 
illustrative purposes, it is the view he eventually appears to endorse. He concedes that it is not obvious what a desire de dicto to do the right thing amounts to, on an expressivist analysis. Making sense of this requires that expressivists explain how normative contents can figure as the contents of other attitudes, which is one aspect of the perennial Frege-Geach problem. Ridge therefore defends the conditional thesis that if expressivists can solve the Frege-Geach problem, they can also solve the problem of accounting for degrees of normative certitude.

Setting aside the prospects of solving the Frege-Geach problem, it is not clear that Ridge's move to a broader account of betting avoids the problems that arise for the narrow focus on monetary bets. It is true of all things we care about that some people care very little or not at all about them, and it is true of many things we care about that they have diminishing marginal utility for us. What is more, using monetary bets has the aformentioned attraction that money is easily subdivided and quantifiable. But this is not true of de dicto desires to do what is right, and it seems in general not true of 'things agents care about'.

Another standard problem with approaches that focus narrowly on monetary bets is that some beliefs are not amenable to them. Consider someone who is confident that there is no monetary institution. Given (ii) and (iii), such a person is disposed to take the bet (€10 if there is no monetary insitution, $€ 0$ if if there is a monetary institution) over the bet ( $€ 0$ if if there is no monetary institution, $€ 10$ if if there is a monetary institution). Given (i), the person's confidence that there is no monetary institution is revealed by her disposition to take the former bet over the latter. But such a disposition is absurd, since some of the possible pay-offs are not well-defined. (If there is no monetary institution, you can't get any monetary pay-off at all!) The belief that there is no monetary institution may be unsupported by evidence, but it is not absurd, and it should be possible define degrees of certitude for this belief.

Ridge's view faces a version of this problem, which he does not address. Consider a cynic who is confident that there is nothing she cares about. On Ridge's broader betting accout, the cynic would be disposed to take a bet that gives her a lot of what she cares about if there is nothing that she cares about, over a bet that gives her a lot of what she cares about if there is something that she cares about. But, again, that is absurd. By contrast, the cynic's belief that there is nothing she cares about may be unfortunate, but it is not absurd and should have a definable degree of certitude.

A third general problem for the attempt to understand degrees of certitude in terms of betting dispositions is that some people are keen to gamble, whereas others are averse to it. But willingness or unwillingness to gamble should clearly not affect one's certitude about various matters. This is clearly a challenge for the view that degrees of certitude supervenes or reduces to betting dispositions, and it suggests that betting dispositions need not be reliable indicators of people's degrees of certitude.

Ridge's view evades this problem because his suggestion is to 'go hypothetical'. More particularly, he might suggest that in order to determine an agent's certitude, we look to the nearest possible world in which the agent has no particular pro- or con-attitudes vis-à-vis gambling, but instead has the dispositions of an instrumentally rational maximizer of expected utility.

It is not clear that such a move is successful, however, for it is in general not clear what bearing non-actual attitudes have on our actual attitudes (Eriksson and Hájek 
2007, p. 189). Why think that the betting behaviour I would have if I had very different attitudes says anything about my actual beliefs? Indeed, Ridge notes that an 'often neglected aspect' of non-cognitivists' problem with normative certitude is that an acceptable account must accommodate the role that certitude (and importance) play in rational motivation. ${ }^{7}$ But it is not clear how an agent's actual rational motivation to act are explained by attitudes she does not actually have but merely could have (had).

At this point, Ridge might respond that the problems we have highlighted are indeed problems for the view that certitude reduces to, or supervenes on, betting dispositions, and for his more specific proposal that normative certitude is to be understood in terms of a desire de dicto to act rightly. Importantly, however, these problems do not demonstrate that there is no plausible account of normative certitude available to quasi-realists. Ridge could say that, if the problems turn out to be insurmountable, the quasi-realist can simply mimic the cognitivist's account, whatever it is. Recall Ridge's claim that if there is a plausible account of certitude-including normative certitude - available to cognitivists, quasi-realists can take on the same account. However, we shall argue in the next section that this is not as easy as it may sound.

\section{Ridge's quasi-realist proposal: normative beliefs as non-representational beliefs}

To motivate the claim that quasi-realists can simply mimic whatever account of certitude cognitivists take to be most plausible, Ridge makes use of a familiar quasi-realist gambit: He points out first that quasi-realists take normative judgements to be truthapt. Since they accept deflationism about truth, quasi-realists can easily maintain that some normative judgements are true. Second, Ridge contends that '[w]ith truth, we have holding true, which is to say normative belief.' (12) Furthermore, Ridge takes 'belief' to refer to a multiply realizable kind: 'Some beliefs are purely representational states, whereas other beliefs are non-representational.' (12) We don't have much of an idea about what non-representational beliefs are, but it seems clear that Ridge thinks that normative beliefs belong in this category.

It is far from obvious, however, that quasi-realists can unproblematically help themselves to any account that cognitivists may accept, simply by plugging in the notion of non-representational beliefs. Consider interpretationism á la David Lewis, which is the general account of certitude that Ridge seems most sympathetic to. On this view, there are only two mental states that we can correctly ascribe to an agent in order to interpret her behaviour-beliefs and desires. We can correctly ascribe beliefs and desires to an agent if she satisfies the axioms or rationality postulates that are constitutive of being a believer and a desirer. Furthermore, if she satisfies these axioms, her credences can be represented by a probability function and her desires

\footnotetext{
7 Ridge considers someone who values a given quantity of pleasure equally as much as she values a particular achievement, but who is more certain that pleasure is good (at all) than the achievement is good (at all). When faced with a choice between doing something that would generate the given amout of pleasure, or something that would constitute having made the particular achievement, she will choose the former insofar as she is fully rational (2018:17).
} 
by a utility function. Crucially, on the most plausible axiomatization, there are two distinct states, beliefs and desires, and the rationality postulates for belief are not the same as the rationality postulates for desire. ${ }^{8}$ For example, desires do not satisfy all of the axioms of the probability calculus. This prompts the following question: which rationality axioms are non-representational normative beliefs supposed to satisfy?

On Ridge's ecumenical expressivist account, normative judgments are 'partly constituted by desire-like states of mind' (2007, p. 133); and yet, they are beliefs, where belief is understood broadly as 'whatever causally regulates our actual use of "belief" (2014, p. 60). Ridge seems to face a dilemma here. On the first horn, if non-representational normative beliefs satisfy the rationality axioms for desires, they should be seen as a sub-class of desires, and Ridge's theory will consequently be as badly equipped to accommodate normative certitude as previous non-cognitivist theories.

On the second horn, non-representational normative beliefs satisfy the rationality axioms for belief, and thus fall in the same class as representational beliefs. But then, it is unclear how non-representational beliefs supposedly differ from representational beliefs. Indeed, if Ridge were to go for an axiomatization that defines graded beliefs directly in terms of betting preferences - to be more certain that $p$ than $q$ when one prefers A to B is just to prefer (A if $\mathrm{p}, \mathrm{B}$ if not-p) to (A if $\mathrm{q}, \mathrm{B}$ if not-q)-then all credences, non-normative as well as normative, would in effect be reduced to betting dispositions, and it would, again, be difficult to see how one can distinguish between desire-like non-representational beliefs and representational beliefs. Quasirealism, therefore, risks collapsing into realism, as is often the case when quasi-realists simply copy the realist's explanations. Also, is not clear how Ridge can now maintain that normative beliefs differ from descriptive ones in that they are motivational in themselves, as he argues elsewhere (2014, p. 57), and as several expressivists have insisted before him.

There is thus a tension between the standard form of intepretationism and the sorts of hybrid states that Ridge's ecumenical expressivism presupposes. ${ }^{9}$ Ridge cannot just help himself to standard forms of interpretationism. He owes us an account of how interpretationism is supposed to accommodate hybrid states that are partly defined by the rationality postulates for belief and partly defined by those for desire. This illustrates that it is not the case that for any view of credence available to cognitivists, quasi-realists can simply take on the same account.

Suppose now that the view of what credences are that will look most promising to cognitivists is metaphysical primitivism, i.e., the view that credences are primitive

\footnotetext{
8 Here we assume an axiomatization that builds on Jeffrey's, but which avoids the well-known problems that afflict Jeffrey's own account (Jeffrey 1978). The Jeffrey axioms, which Lewis also accept (Lewis 1974), do not establish that credences are probabilistically coherent. Nor do they show that there is a unique utility representation of desires when a unit and a zero point is fixed. These problems are avoided by the account presented in Joyce (1999), which posits two distinct mental states, beliefs and desires, and provides separate axioms for each.

9 Indeed, Lewis actually attacks the position that beliefs that a certain thing is good can play the functional roles of both beliefs and desires. He argues that this is not, in general, possible, because beliefs and desires update in different ways (Lewis 1988).
} 
properties of belief. Ridge expresses some doubt as to whether quasi-realism is compatible with primitivism (2018, p. 16). But, he repeats that quasi-realists do not deny that there are normative beliefs. He therefore infers that insofar as there is trouble for quasi-realism here, it would have to be that only representational beliefs can come in degrees, or that only representational beliefs can have the primitive property of being a gradable belief state. Ridge's response to this potential objection is to ask why we should believe that: 'Some argument is needed; nothing here is obvious.' (2018, p. 15)

While we are inclined to agree with at least the second half of this claim, we think that the dialectical situation still leaves a good deal of explanatory work to do for quasi-realists. The onus is on them to $(a)$ explain what non-representational beliefs are, and in particular how they differ from desires and representational beliefs; $(b)$ make plausible that there are such beliefs; and $(c)$ give a plausible argument to the effect that non-representational beliefs vary in degrees. Needless to say, cognitivists face none of the difficulties in $(a)-(c)$, since they never insisted that normative and non-normative beliefs are different in kind (in addition to content).

We conclude that cognitivists still have the upper-hand over quasi-realists in the debate concerning normative certitude. Whatever certitude turns out to be exactly, it seems that non-cognitivists and expressivists will have a hard time accommodating it for normative judgements. The quasi-realist gambit does not in the end enable them to steer clear of these difficulties.

Acknowledgements Open access funding was provided by Stockholm University. Earlier versions have been presented at seminars in Lund and Uppsala, at a workshop on normative pluralism in Tromsö, and at the 2019 Swedish Congress of Philosophy in Umeå. We are grateful for all the helpful comments from participants at these events.

Open Access This article is licensed under a Creative Commons Attribution 4.0 International License, which permits use, sharing, adaptation, distribution and reproduction in any medium or format, as long as you give appropriate credit to the original author(s) and the source, provide a link to the Creative Commons licence, and indicate if changes were made. The images or other third party material in this article are included in the article's Creative Commons licence, unless indicated otherwise in a credit line to the material. If material is not included in the article's Creative Commons licence and your intended use is not permitted by statutory regulation or exceeds the permitted use, you will need to obtain permission directly from the copyright holder. To view a copy of this licence, visit http://creativecommons.org/licenses/by/4.0/.

\section{References}

Bykvist, K., \& Olson, J. (2009). Expressivism and moral certitude. The Philosophical Quarterly, 59, $202-215$.

Bykvist, K., \& Olson, J. (2012). Against the being for account of normative certitude. Journal of Ethics and Social Philosophy, 6, 1-8.

Bykvist, K., \& Olson, J. (2017). Non-cognitivism and fundamental moral certitude: A reply to Eriksson and Francén Olinder. Australasian Journal of Philosophy, 95, 794-799.

Eriksson, J., \& Francén Olinder, R. (2016). Non-cognitivism and the classification account of moral uncertainty. Australasian Journal of Philosophy, 94, 719-735.

Eriksson, L., \& Hájek, A. (2007). What are degrees of belief? Studia Logica, 86, 183-213.

Jeffrey, R. (1978). Axiomatizing the logic of decision. In C. Hooker, J. Leach, \& E. McClennen (Eds.), Foundations and applications of decision theory (Vol. 1, pp. 227-231). Dordrect: Reidel.

Joyce, J. (1999). The foundations of causal decision theory. Cambridge: Cambridge University Press. 
Lenman, J. (2003). 'Non-cognitivism and the dimensions of evaluative judgment'. Brown electronic article review service. Retrieved January 30, 2020, from http://www.brown.edu/Departments/Philosophy/ bears/homepage.html.

Lewis, D. (1974). Radical interpretation. Synthese, 27, 331-344.

Lewis, D. (1988). Desire as belief. Mind, 97, 323-332.

Ramsey, F (1926). Truth and Probability, in Ramsey (1931). in R. B. Braithwaite (Ed.), The foundations of mathematics and other logical Essays. Ch. VII (pp. 156-198). London: Kegan, Paul, Trench, Trubner $\&$ Co., New York: Harcourt, Brace and Company.

Ridge, M. (2003). Certitude, importance and robustness for non-cognitivists. Brown electronic article review service. Retrieved January 30, 2020, from https://www.brown.edu/Departments/Philosophy/ bears/0301ridg.html.

Ridge, M. (2007). Ecumenical expressivism: The best of both worlds? In R. Shafer-Landau (Ed.), Oxford studies in metaethics (Vol. 2, pp. 51-76). Oxford: Oxford University Press.

Ridge, M. (2014). Impassioned belief. Oxford: Oxford University Press.

Ridge, M. (2018). Normative certitude for expressivists. Synthese. https://doi.org/10.1007/s11229-018$1884-7$.

Sepielli, A. (2012). Normative uncertainty for non-cognitivists. Philosophical Studies, 160, 191-207.

Smith, M. (2002). Evaluation, uncertainty, and motivation. Ethical Theory and Moral Practice, 5, 305-320.

Publisher's Note Springer Nature remains neutral with regard to jurisdictional claims in published maps and institutional affiliations. 